\title{
WHITE CEREBELLUM SIGN. CASE SERIES AND LITERATURE REVIEW
}

\author{
Carlos Umberto Pereira ${ }^{1}$, André Fabiano de Carvalho², Nicollas Nunes Rabelo³, Gabriela \\ Ferreira Kalkmann ${ }^{4}$, Letícia Novak Crestani ${ }^{5}$, Leticia Adrielle dos Santos
}

Received: 19 July 2020 / Published: 28 October 2020

\begin{abstract}
Introduction: The white cerebellum sign is a rare radiological finding, seen in severe traumatic brain injury and severe hypoxia. Radiologically, it is characterized by cerebellar hyperdensity, associated with diffuse cerebral hemispheres hypoattenuation. This paper aims to guide the white cerebellum sign diagnosis in traumatic craniocerebral injuries or not in pediatric patients.

Patients and Methods: The authors present a series of five cases that showed the white cerebellum sign from the period about 2007 and 2010, associated with a literature review. Results: The white cerebellum sign was present in 5 patients, three of them were male and 2 females. The mean age was 22 months. The causes of which were: traumatic brain injury (3), drowning (1) and metabolic encephalopathy (1). The skull computerized tomography scan was performed in all cases. All patients were submitted to conservative treatment. There were four deaths and one survived with severe neurological sequelae.

Conclusion: The white cerebellum sign is associated with irreversible brain damage, and its pathophysiology is controversial. The imaging tests are important to diagnosis. It has a poor prognosis, associated with the development of diffuse cerebral atrophy or cystic encephalomalacia in those who survive.
\end{abstract}

Key words: Cerebellum, Neuroimaging, Prognosis, Traumatic Brain Injury, White cerebellum sign

${ }^{1}$ Departament of Neurosurgery, Sergipe Emergency Hospital.

Preceptor of the Neurosurgery Residency at Surgery Hospital Charitable Foundation. Aracaju - Sergipe, Brazil.

${ }^{2}$ Radiology Service at Sergipe Emergency Hospital and Sergipe

Integrated Medicine Center. Aracaju - Sergipe, Brazil.

${ }^{3}$ Neurosurgery Department. UniAtenas University Center.

Paracatu - Minas Gerais, Brazil.

${ }^{4}$ Federal University of Paraná. Curitiba - Paraná, Brasil.

${ }^{5}$ Medicine Faculty of the Maringá University Center. Maringá -

Paraná, Brasil.

${ }^{6}$ Federal University of Sergipe. Aracaju - Sergipe, Brazil.

To whom correspondence should be addressed: Carlos Umberto Pereira, MD, PhD [E-mail: umberto@infonet.com.br]

Journal homepage: www.sbnped.com.br

\section{Introduction}

The white cerebellum sign is described as a diffuse hypoattenuation of the cerebral parenchyma $[1,2,3]$ due to cerebral edema, with preservation of the density of the cerebellum, thalamus and brainstem [1], resulting in an apparent hyperattenuation of this structure compared to the cerebral hemispheres [2]. It is a classic and rare radiological finding [3], which presents a wide variety of causes [4], although the most common etiology is severe extracerebral hypoxia [5]. It mainly affects children from birth to two years of age, and has a poor prognosis [6].

Although cerebellar damage is seen in neonates, it tends to be more common in older children. The reason for this prevalence has not been clarified, but it is suggested that the hypoxic event duration and severity, and immaturity of Purkinje cells in neonates protects the cerebellar cortex, as these cells are highly sensitive to ischemia, due the inability to generate energy during a anoxia event [7]. Huang et al [8] explain that the greater involvement of the deep gray substance, occurs because this area is actively myelinated, with greater regional energy requirement, and has higher concentrations of NMDA receptors $(\mathrm{N}-$ methyl-D-aspartate), therefore, it is an area more susceptible to hypoxia.

The authors present five cases of white cerebellum sign, describing the pathophysiology, diagnosis, treatment and prognosis. Aiming to guide the white cerebellum sign diagnosis in traumatic craniocerebral injuries or not in pediatric patients.

\section{Patients and Methods}

Retrospective study of five patients who presented the white cerebellum sign on the radiological examination, admitted at Emergency Hospital 
(Aracaju - Sergipe, Brazil), between 2007 and 2010. The following aspects were analyzed: age, sex, predisposing causes, clinical picture, imaging tests, clinical therapy and prognosis.

The literature review was conducted using the following international databases: PubMed, Scielo, Scientific Direct, Ebsco, LILACS, TripDataBase and Cochrane, using the descriptors: White Cerebellum and Reversal Sign. Articles from the period of 1977 to 2020 were selected, resulting in a total of 31 articles, which met the inclusion criteria for articles related to the white cerebellar signal and inversion signal in the imaging exams. Since, during the searches, articles related to the cerebellum were found, but without correlation with the proposed theme.

\section{Results}

Five patients were analyzed in the pediatric Intensive Care Unit at Sergipe Emergence Hospital (Aracaju-Sergipe, Brazil), during the period from 2007 to 2010. Three patients were male and two female. The ages varied between 16 and 26 months, with an average of 22 months. The causes were: traumatic brain injury (TBI) associated to automobilistic accident (3), cardiorespiratory arrest due to drowning (1) and metabolic encephalopathy (1). All of them underwent a skull computed tomography (CT), in which revealed supratentorial hypodensity, cerebral edema and infratentorial hyperdensity (Figures. 1, 2a and 2b, 3a, $3 b$ and $3 c$ ), and in all cases the CT was performed after the emergency patient's stability, except in the case with metabolic encephalopathy diagnosis, in which the test performance delay occurred due to bureaucratic situations. All were submitted to conservative treatment. Four patients died, and one survived with Glasgow Outcome Scale 3 (Table 1).

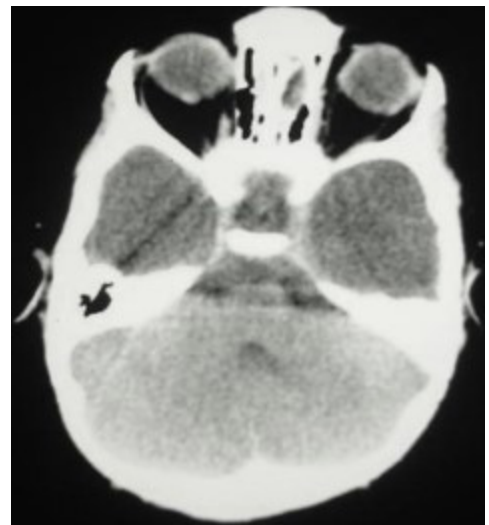

Figure 1. Axial section of skull computerized tomography without contrast showing supratentorial hypodensity, diffuse cerebral edema and hyperdensity of the cerebellar parenchyma.

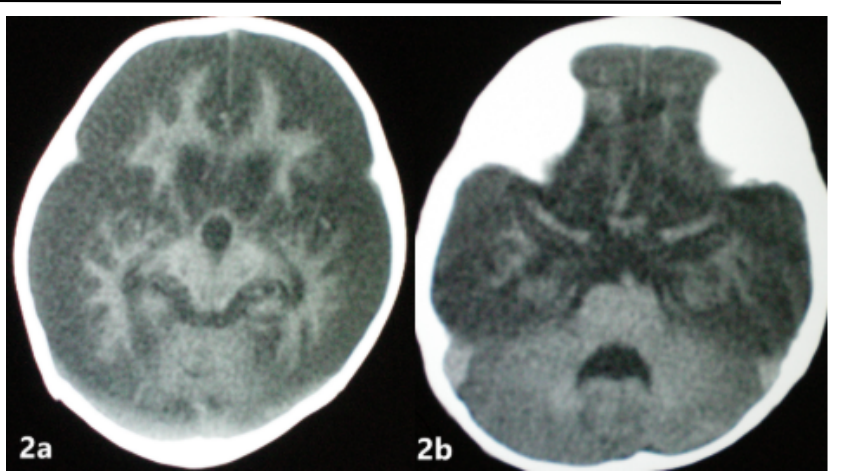

Figures $2 \mathrm{a}$ and $2 \mathrm{~b}$. Skull Computerized Tomography without contrast in axial section showing: $2 a$ - Reduction in the density of the cerebral cortex (gray matter) and relative increase in white matter. $2 \mathrm{~b}$ - cerebellar hyperdensity. Tomographically compatible as a reverse sign characteristic of diffuse cerebral anoxia.

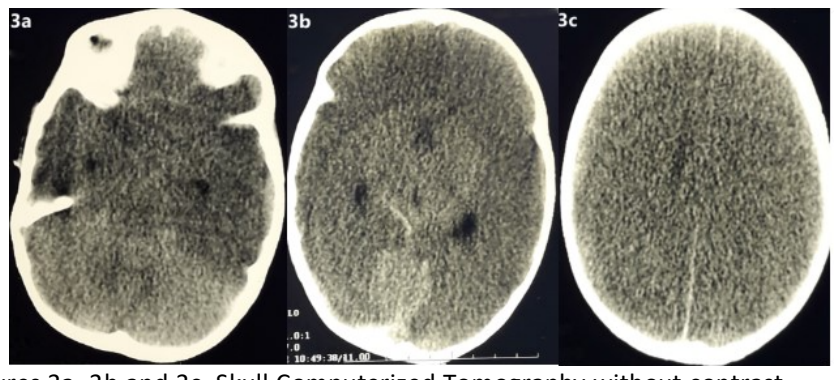

Figures 3a, 3b and 3c. Skull Computerized Tomography without contrast in axial section showing: 3a - Supratentorial hypodensity and infratentorial hyperdensity. $3 b$ - Deletion of sulcus and fissures in the cerebral hemispheres, associated with a decrease in the cerebral ventricles. 3c - Diffuse cerebral edema with absence of brain sulcus.

\section{Discussion}

\section{Causes}

Diffuse cerebral edema occurs in $10 \%$ to $20 \%$ of severe TBI in adult patients [1], and twice as common in children when compared to adults [9].

The white cerebellum sign is frequently seen in children with diffuse brain lesions [9] as in cases of severe hypoxia (asphyxia in childbirth [4], epileptic status, cardiorespiratory arrest, tuberous sclerosis [11] and drowning), as well in trauma (mistreatment, especially in childhood) and infection (bacterial meningitis and encephalitis) $[2,6,12,13]$. This sign is uncommon in adults, but can be seen after cardiac arrest [14] and postpartum epilepsy [10]. A small percentage of patients who suffer from global brain hypoxia develop density reversal between gray and white parenchyma, as evidenced by computed tomography (CT) [15]. Severe TBI as a cause of the white cerebellum sign is rare. Han et al [6] analyzed twenty children with reverse sign and found as causes: hypoxia/anoxia in nine cases, maltreatment (7), TBI (2), bacterial encephalitis (1) and degenerative encephalitis (1). In our series, patients were aged between 16 and 26 months, and the causes found for the white cerebellum sign development were TBI (3), drowning (1) and metabolic encephalopathy (1). 
Hypoxic-ischemic brain injuries in children and young people are usually the result of drowning, suffocation or non-accidental trauma [8]. Nonaccidental brain injury (NABI) is considered the most frequent cause of traumatic injuries in children, resulting in $80 \%$ of deaths from TBI in children under two years of age $[16,17]$. A clinical presentation of $\mathrm{NABI}$, can be non-specific; in a direct questionnaire, it frequently occurs in the history of secondary $\mathrm{TBI}$, but not consistent with the injuries found [18].

Barnes et al [16] defines NABI as a bodily injury whether intentionally or unintentionally inflicted on the child, characterized by the triad subdural hemorrhage, retinal hemorrhage and encephalopathy, in the context of an inadequate or inconsistent history, usually without witnesses, and often accompanied by other injuries apparently caused. Younger children tend to be more susceptible to severe brain injuries caused by NABI than injuries from accidental trauma [18]. This fact can be explained through the biomechanical study of the lesion in which it can be seen that the forces involved in NABI tend to be repetitive and often associated with rotational deceleration, leading to brain injury up to 50 times greater than that caused by falls from small accidental heights or injuries [17].

\section{Physiopathology}

The pathophysiology of the white cerebellum sign is controversial [1,11]. One of the mechanisms proposed by Bird et al [12] would be the distention of the deep medullary veins associated with central venous congestion in contrast to peripheral cortical edema. Congestion is secondary to partial obstruction of the venous flow due to increased intracranial pressure (IP). The increase in IP is due to the stop in the synthesis of Adenosine Triphosphate (ATP), with consequent interruption of the sodium pump, leading to the influx of water, causing vasogenic edema in the white matter and brain cortex [4]. Another proposed theory is the preference of blood flow for posterior circulation in cases of cerebral hypoxia [12]. Lowdensity changes appear in the areas most vulnerable to hypoperfusion [15].

Anoxia and ischemia elevate brain glucose, causing a predilection for lesion of the cerebral cortex and basal ganglia [15], which suffer a decrease with consequent loss of differentiation between gray and

Table 1. Clinical-epidemiological characteristics of five patients with a white cerebellum sign

\begin{tabular}{|c|c|c|c|c|c|}
\hline Case & Sex & Age & Cause & Finds in CT & Results \\
\hline 1 & Male & 16-months & Drowning-CA & $\begin{array}{c}\text { Supratentorial } \\
\text { hypodensity and } \\
\text { cerebellar } \\
\text { hyperdensity }\end{array}$ & Death \\
\hline 2 & Male & 18-months & $\mathrm{TBI}$ & $\begin{array}{c}\text { Diffuse } \\
\text { supratentorial } \\
\text { hypodensity, } \\
\text { effacement of } \\
\text { cisterns and } \\
\text { brain grooves, } \\
\text { associated with } \\
\text { cerebellar } \\
\text { hyperdensity }\end{array}$ & Death \\
\hline 3 & Male & 26-months & $\mathrm{TBI}$ & $\begin{array}{l}\text { Supratentorial } \\
\text { hypodensity, } \\
\text { diffuse cerebral } \\
\text { edema and } \\
\text { cerebellar } \\
\text { hyperdensity }\end{array}$ & Death \\
\hline 4 & Female & 22-months & $\mathrm{TBI}$ & $\begin{array}{l}\text { Supratentorial } \\
\text { hypodensity, } \\
\text { cerebral edema, } \\
\text { and cerebellar } \\
\text { hyperdensity }\end{array}$ & Death \\
\hline 5 & Female & 19-months & $\begin{array}{c}\text { Metabolic } \\
\text { encephalitis }\end{array}$ & $\begin{array}{l}\text { Supratentorial } \\
\text { hypodensity, } \\
\text { diffuse cerebral } \\
\text { edema and } \\
\text { infratentorial } \\
\text { hyperdensity }\end{array}$ & $\begin{array}{c}\text { GOS } 3 \text { associated } \\
\text { with cerebral } \\
\text { atrophy }\end{array}$ \\
\hline
\end{tabular}

Legends: CA - Cardiac Arrest; TBI - Traumatic Brain Injury; GOS - Glasgow Outcome Scale. 
white brain parenchyma [4]. Basal ganglia and brain cortex have a high metabolic activity, are vulnerable to hypoxia and tissue hypoperfusion, and the density decreases with loss of the normal difference between the white and gray parenchyma, sometimes the density loss is so great that it occurs the development of the reverse signal [15]. Another theory for the white cerebellum sign is the increased capillary proliferation in central regions with ischemia [14].

Diffuse and bilateral cerebral edema causes a homogeneous density reduction of the cerebral hemispheres. In contrast, the cerebellum and infratentorial structures density is preserved, resulting in an apparent density increase of these structures compared to the supratentorial region, being thus called the white cerebellum sign [9].

Myers et al [19] suggest that transtentorial herniation through the notch, caused by acute cerebral edema, partially relieves the increase in IP, improving the perfusion of central structures such as the brainstem and cerebellum, preventing necrosis [15]. However, this theory is questioned, since there is the preservation of the attenuation of basal ganglia, thalamus, and posterior fossa before transtentorial herniation [20]. Kavanagh et al [21] suggest that preferential maintenance of blood flow in posterior circulation is developed in relation to the anterior circulation in cases of cerebral hypoxia, relatively preserving the attenuation in posterior fossa. Myers et al [19] suggest that the increase in blood glucose during the anoxia/ischemia period causes preferential damage to the cerebral hemispheres.

The autopsy of children who presented the reverse sign showed petechiae in the brainstem and cerebellum, in addition to slight neuronal changes and mild edema in that region, associated with acute neuronal necrosis and marked edema in the cerebral cortex and white matter [6]. Thus, Kavanagh et al [21] reported that petechiae can contribute to the hyperattenuation of these areas. Harwood-Nash et al [2] assumes that the white cerebellum sign is due to the diver's primitive reflex, seen in animals in hibernation and during diving at great depths. The diver's primitive reflex is associated with ancient cardiorespiratory reflexes classes, as the autonomic reflexes override the normal reflex control of arterial blood gases and pressure, arrhythmia, peripheral vasoconstriction, and redistribution of blood flow to the vital organs, as a protection against hypoxia [22].

\section{Diagnosis}

Some authors consider the white cerebellar signal as a variant of the reverse signal $[5,23]$, but both can be seen on CT in association or not [3]. The inversion sign is seen on CT without contrast as an image in which the normal relationship between gray and white parenchyma occurs; the gray matter presents relative hypoattenuation in relation to the adjacent white matter $[2,3,20,24]$. Showing a relative increase in the density of the cerebellum, basal ganglia and thalamus [25].

Because it is a relatively quick exam and widely available, CT is the method of choice in the acute phase of neurotrauma, allowing the detection of bone fractures and intracranial injuries, as well as the assessment of the need for neurosurgical intervention [26]. Only a small percentage of patients show a "reverse sign" on CT within the first 24 hours after brain injury, although imaging studies can be negative if performed at very early stages [27].

In CT the diffuse cerebral edema manifests as a homogeneous hypoattenuation associated with the loss of distinction between gray and white matter and, in children, the white cerebellum sign can be found with the relative hyperattenuation of the cerebellar parenchyma [28]. Other signs of diffuse cerebral edema are the absence of cortical grooves, erasure of basal cisterns, especially the perimesencephalic cisterns and bilateral compression of the lateral ventricles [29]. In cases of severe hypoxia, CT in the chronic phase will demonstrate diffuse atrophy of cerebral parenchyma, associated with enlargement of the cerebral folds and ventricular dilation [30,31]. All patients in the present study underwent CT, in which they were found in which revealed supratentorial hypodensity, cerebral edema and infratentorial hyperdensity.

Magnetic resonance imaging (MRI) has less sensitivity for acute bleeding compared to $\mathrm{CT}$, requires more time to perform and, in children, usually requires sedation [26]. However, when combined with the diffusion technique or with proton spectroscopy, and measurement of apparent diffusion coefficient, MRI becomes the most sensitive modality for the early diagnosis of cerebral hypoxia $[8,10,23]$. It will often show hypersignal to diffusion within the first 12 and 24 hours after hypoxic/ischemic event [32].

\section{Treatment}

The treatment is basically symptomatic, such as reducing intracranial hypertension and reversing ischemic injury [1]. The resolution of severe hypoxia includes hypothermia and administration of excitatory amino acids. Although treatment is effectively limited, early detection of brain damage is important. Neuroimaging studies are important as they inform about the extent and severity of the injury and can predict the outcome in long term, since hypoxia causes irreversible brain damage and has a poor prognosis [8].

\section{Complications and prognosis}

There are two types of brain damage after anoxia with preservation signs of central structures: increased oxygenation of the thalamus and basal ganglia in newborns suffering from perinatal asphyxia; And, increased attenuation of the basal ganglia and 
thalamus, and enhancement with medium contrast in severe cerebral ischemia. Both occur after 1 to 2 weeks of anoxia [10].

The white cerebellum sign is associated with a poor prognosis, severe permanent brain injury $[10,14]$, development of diffuse atrophy and cystic encephalomalacia [15]. One third of the patients who present this sign on CT, evolve to death [10].

\section{Conclusion}

The white cerebellum sign is a rare radiological finding, seen mainly in cases of pediatric cerebral hypoxia; in our series the most common cause was TBI. Being of great importance, its recognition for the fast and precise conduct associated with the monitoring of the condition, in order to decrease the rates of poor prognosis, since those who survive, often develop diffuse cerebral atrophy, cystic encephalomalacia, or as one of the patient in the present case series, in which occurred Glasgow Outcome Scale 3 development.

\section{Disclosure Statement}

The authors have no conflicts of interest to declare.

\section{Funding statement}

\section{None.}

\section{References}

1. Mbaba AN, Abam R, Ogolodom MP. White cerebellum sign - An ominous radiological imaging finding: A case report and review of the literature. Biomedical: J Scient Techn Res. 2019;15(1):11159-61. DOI: 10.26717/BJSTR.2019.15.002659

2. Harwood-Nash DC. Abuse to the Pediatric Central Nervous System. AJNR Am J Neuroradiol. 1992;13(2):569-75.

3. Gunkel J, Scholtens AE, Heldt J. The white cerebellum sign. Netherlands J Crit Care. 2020;28(2):107.

4. Mba SE, Kalangu K, Musara A, Ndlovu D, Zimani NH. White cerebellum sign after ventriculo-peritoneal shunt insertion: A case report and review of literature. Inter $\mathbf{J}$ Neurosurg. 2018;2(2):31-4. DOI: 10.11648/j.ijn.20180202.13

5. Dwarakanath S, Bansal A, Rudrappa S, Gopal S, Venkataramana NK. White cerebellum sign. A case report and review of literature. J Pediatr Neurosci. 2006;1(3):22-3.

6. Han BK, Towbin RB, De Courten-Myers G, McLaurin RL, Ball WS Jr. Reversal sign in CT: Effect of anoxia/ischemic cerebral injury in children. AJR. 1990; 154(2):361-8. DOI: 10.2214/ajr.154.2.2105031

7. Castillo M. Selective vulnerability and the cerebellum in neonates. AJNR Am J Neuroradiol. 2007;28(1):20-1.

8. Huang B Y., Castillo M. Hypoxic-Ischemic Brain Injury: Imaging Findings from Birth to Adulthood. RadioGraphics. 2008;28(2):417-39. DOI: 10.1148/rg.282075066

9. Osborn AG. "Craniocerebral Trauma". In: Osborn AG (ed). Diagnostic Neuroradiology. 1st Edn. Chapter: Elsevier, 1994. p. 199-247.
10. Castro LJ, Aguirre HD, Posada AF, Labrador CS. Signo del cerebelo blanco o signo reverso. Neurología Argentina. 2014;6(3):160-3. DOI: 10.1016/j.neuarg.2014.04.001

11. Baby N, Gilvaz O, Kuriakose AN. White cerebellum sign: A poor prognostic sign. Pediatric Neurology. 2019;101:86-7. DOI: 10.1016/j.pediatrneurol.2019.03.024

12. Bird CR, Drayer BP, Gilles FH. Pathophysiology of reverse edema in global cerebral ischemia. AJNR Am J Neuroradiol. 1989;10(1):95-8.

13. Vergote G, Vandeperre H, De Man R. The reversal sign. Neuroradiology. 1992;34:215-6. DOI: 10.1007/BF00596339

14. Malik MV, Murthy BTVSP, Raj LCV, Vyas MS, Mehar MUSSV. 'White cerebellum sign' in immediate postpartum period. Med J Armed Forces India. 2015;71(Suppl 1):s1635. DOI: $10.1016 /$ j.mjafi.2013.10.018

15. Moosa S, Andronikou S. Hypoxic-ischaemic injury: the 'white cerebellum sign' versus the true 'reversal sign'. SA J Radiol. 2005;9(1):32-3.

16. Barnes PD. Imaging of Nonaccidental Injury and the Mimics: Issues and Controversies in the Era of EvidenceBased Medicine. Radiol Clin N Am. 2011;49(1):205-29. DOI: 10.1016/j.rcl.2010.08.001

17. Eberhard MEF, Posel G, Mora XD, Vergara MFA. Maltrato infantil, TEC y diagnóstico por imágenes. Rev Chil Pediatr. 2011;82(3):231-7. DOI: 10.4067/S037041062011000300009

18. Rajaram S, Batty R, Rittey CDC, Griffiths PD, Conolly DJA. Neuroimaging in non-accidental head injury in children: an important element of assessment. Postgrad Med J. 2011;87(1207):355-61. DOI: 10.1136/pgmj.2010.103150

19. Myers RE. Experimental models of perinatal brain damage: relevance to human pathology. In: Gluck L (ed), Intrauterine asphyxia and the develop brain. Year Book Med: Chicago; 1977. p. 37-97.

20. Chen CJ. Central structure preservation of the reversal sign. Neuroradiology. 1999;41(12):946-8. DOI: $10.1007 / \mathrm{s} 002340050873$

21. Kavanagh EC. The Reversal Sign. Radiology. 2007;245(3):914-5. DOI: 10.1148/radiol.2453050112

22. Oppenheimer S. Human's association with water bodies: The 'Exaggerated Diving Reflex' and its relationship with the evolutionary allometry of human pelvic and brain sizes. Human Evolution 2013;28(3-4):137-170.

23. Wan AYH, Shum JSF, Lo SSW, Lee JCK, Sy ANL, Chu CY, Ka SYJ, Cheng SCS. Computed Tomography of Hypoxic-ischaemic Brain Injury in Infants, Children, and Adults: Three Illustrative Cases and Literature Review. Hong Kong J Radiol. 2011;14:44-8.

24. Chavhan GB, Sroff MM. Twenty classic signs in neuroradiology: A pictorial essay. Indian J Radiol Imaging. 2009;19(2):135-45. DOI: 10.4103/0971-3026.50835

25. Gonçalves FG, Barra FR, Matos VL, Jovem CL, Amaral LLFA, Carpio-O'Donovan R. Sinais em neurorradiologia Parte 1. Radiol Bras. 2011;44(2):123-8. DOI: 10.1590/S0100-39842011000200013

26. Sieswerda-Hoogendoorn T, Boos S, Spivack B, Bilo, RAC, Rijn RR. Abusive Head Trauma Part II: Radiological aspects. Eur J Pediatr. 2012; 171(4):617-23. DOI: 10.1007/s00431-011-1611-6

27. Barkovich AJ. Brain and spine injuries in infancy and childhood. In: Barkovich AJ, ed. Pediatric neuroimaging. 4th ed. Philadelphia, Pa: Lippincott Williams \& Wilkins; 2005. p. $190-290$.

28. Lonergan GJ, Baker AM, Moreu MK, Boos SC. From the archives of the AFIP. Child Abuse: Radiologic-Pathologic Correlation. Radiographics. 2003; 23(4):811-45. DOI: 10.1148/rg.234035030 
29. Toyama Y, Kobayashi T, Nishiyama Y, Satoh K, Ohkawa M, Seki K. CT for acute stage of closed head injury.

Radiation Medicine. 2005;23(5):309-16.

30. Taylor SB, Quencer RM, Holzman BH, Naidich TP. Central nervous system anoxic-ischemic insult in children due to near-drowning. Radiology. 1985;156(3):641-6. DOI: 10.1148/radiology.156.3.4023222
31. Fitch SJ, Gerald B, Magill HL, Tonkin ILD. Central nervous system hypoxia in children due to near-drowning. Radiology. 1985;156(3):647-50. DOI:

10.1148/radiology.156.3.4023223

32. Grant PE,Yu D. Acute injury to the immature brain with hypoxia with or without hypoperfusion. Radiol Clin North Am. 2006;44(1):63-77. DOI: 10.1016/j.rcl.2005.08.001 